\title{
Hereditary thrombophilia due to congenital antithrombin deficiency
}

INSERM

\section{Source}

INSERM. (1999). Orphanet: an online rare disease and orphan drug data base. Hereditary thrombophilia due to congenital antithrombin deficiency. ORPHA:82

Hereditary thrombophilia due to congenital antithrombin deficiency is a rare, genetic, hematological disease characterized by decreased levels of antithrombin activity in plasma resulting in impaired inactivation of thrombin and factor Xa. Patients have an increased risk for venous thromboembolism, usually in the deep veins of the arms, legs and pulmonary system and, on occasion, in other venous territories (e.g. cerebral veins or sinus, mesenteric, portal, hepatic, renal and/or retinal veins). 